\title{
Evaluation of Laboratory Application of Camelid Sera Containing Heavy-Chain Polyclonal Antibody Against Recombinant Cytotoxic T-Lymphocyte-Associated Protein-4
}

\author{
Nazli Sotoudeh,, Zahra Noormohammadi, ${ }^{1}$ Mahdi Habibi-Anbouhi, ${ }^{2}$ \\ Fatemeh Kazemi-Lomedasht, ${ }^{3}$ and Mahdi Behdani ${ }^{3,4}$
}

\begin{abstract}
Cytotoxic T-lymphocyte-associated protein-4 (CTLA-4) is a critical negative immunomodulatory receptor that is normally expressed in activated T cells and noticeably, in many cancerous cells. Indeed, molecular detection of CTLA-4 protein is crucial in basic research. In this work, the extracellular domain of the human CTLA-4 (hCTLA-4) protein was cloned, expressed, and purified. Subsequently, this protein was used as an antigen for camel (Camelus dromedarius) immunization to obtain polyclonal camelid sera against this protein. Furthermore, we evaluated the benefits of applying camelid hyperimmune sera containing heavy-chain antibodies in different antibody-based techniques. Our results indicated that hCTLA-4 protein was successfully expressed in the prokaryotic system. The polyclonal antibody $(\mathrm{pAb})$ that raised against recombinant hCTLA-4 protein was able to detect the CTLA-4 protein in antibody-based techniques, such as enzyme-linked immunosorbent assay, western blotting, flow cytometry and immunohistochemistry (IHC) staining. This study shows that, due to the advantages such as multi-epitope-binding ability, camelid pAbs are potent to efficiently apply for molecular detection of CTLA-4 receptors in fundamental antibody-based researches such as IHC.
\end{abstract}

Keywords: camelid hyperimmune sera, cytotoxic T-lymphocyte-associated protein-4, polyclonal antibody, camelid heavy-chain antibodies, immunohistochemistry

\section{Introduction}

C YTOTOXIC T-LYMPHOCYTE-ASSOCIATED PROTEIN-4 (CTLA4) or CD159 is a negative immunomodulatory receptor and belongs to the immunoglobulin superfamily. ${ }^{(1-3)}$ They are expressed on the surface of murine and human-activated $\mathrm{T}$ cells and negatively regulates the activity of $T$ cell response. In fact, CTLA-4 is the main human immune checkpoint that provides peripheral tolerance. ${ }^{(4,5)}$ In the early stages of $\mathrm{T}$ cell activation, the initial surface expression level of CTLA-4 is low. ${ }^{(6)}$ After 2 to 3 days of T cell activation, CTLA-4 is upregulated and reaches the maximum level. ${ }^{(6)}$ Then CTLA-4 receptors bind to the B7 ligands, expressed on antigenpresenting cells and induce the inhibitory signals. ${ }^{(6,7)}$ Significantly, dysregulation of inhibitory checkpoint receptors, including CTLA-4, is one of the tumor-mediated ways to evade immune surveillance. ${ }^{(8,9)}$ Moreover, the upregulation of CTLA-4 is not only indicated in activated T cells but also cancerous cells and tumor-derived cell lines. ${ }^{(10-12)}$ This can underline the imperative role of CTLA- 4 in tumor progression through immune system evasion. ${ }^{(11-13)}$ In fact, CTLA-4 is a noticeable immunologic biomarker with a negative prognostic role in different cancers and solid tumors. ${ }^{(12,14-18)}$ Hence, molecular detecting of CTLA-4 protein is an important goal in many fundamental types of research.

Recently, antibodies have become the routine essential reagents in numerous immunotherapy and immunoassay experiments. ${ }^{(19)}$ Considering the advantages and disadvantages of polyclonal antibodies (pAbs) in comparison with monoclonal antibodies (mAbs), they represent the main valuable commercial research antibodies. ${ }^{(20,21)}$ In this regard, different animals are being used for pAbs production, such as mouse, goat, sheep, horse, rabbit, and camel. ${ }^{(22)}$ Camelid sera contain two kinds of antibodies; conventional antibodies and heavy-chain antibodies (HcAbs). HcAbs belong to a group of immunoglobulin $\mathrm{G}$ (IgG) antibodies with a homodimeric structure. They are formed of two identical heavy chains, but no light chains. Besides, they have two constant domains, $\mathrm{CH} 2$ and $\mathrm{CH} 3$, which are homologous with $\mathrm{Fc}$ domain of conventional antibodies and lack the $\mathrm{CH} 1$ domain. ${ }^{(23)}$ The

\footnotetext{
${ }^{1}$ Department of Biology, Science and Research Branch, Islamic Azad University, Tehran, Iran.

${ }^{2}$ National Cell Bank of Iran, Pasteur Institute of Iran, Tehran, Iran.

${ }^{3}$ Biotechnology Research Center, Venom and Biotherapeutics Molecules Laboratory, Pasteur Institute of Iran, Tehran, Iran.

${ }^{4}$ Zoonoses Research Center, Pasteur Institute of Iran, Amol, Iran.
} 
antigen-binding site of $\mathrm{HcAbs}$ is very unique and contains a high variable domain called $\mathrm{VHH}$ or nanoantibody or $\mathrm{Na}-$ nobody ${ }^{\circledR}(\mathrm{Nb})$. VHH domains are very small $(\sim 15-17 \mathrm{kDa})$, with high solubility and resistant to high temperature, high pressure, and low $\mathrm{pH}^{(24,25)}$

Considering the benefits of camelid polyclonal HcAbs, we cloned and expressed the recombinant extracellular domain of the CTLA-4 receptor gene in Escherichia coli BL21. Next, a Camelus dromedarius was immunized with purified recombinant CTLA-4 protein to produce polyclonal $\mathrm{HcAb}$ against the extracellular domain of CTLA-4 protein. Following that, the application of camelid anti-CTLA-4 antibodies was evaluated. To the best of our knowledge, this is the first report of using camelid pAbs to evaluate their ability in detecting CTLA-4-positive cells on paraffin-embedded section of breast cancer tissue slides through immunohistochemistry (IHC) staining.

\section{Materials and Methods}

\section{Cloning, expression, and purification of human CTLA-4}

The extracellular domain of human CTLA-4 (hCTLA-4, UniprotKB P16410) gene containing His-tag, cloned in pGH vector, was purchased (Biomatik Canada) and named hCTLA-4-pGH. The standard cloning procedure was followed to subclone the $h C T L A-4$ gene into pET26b vector. Briefly, NdeI and XhoI digestion was performed on hCTLA4-pGH and pET26b vectors followed by ligation with T4 ligase. The ligated product was transformed into $E$. coli Top 10F' and single colonies were screened with colony polymerase chain reaction (PCR), using universal T7 primers and confirmed by enzymatic digestion. Sequencing results with T7 universal primers showed $100 \%$ identity with our expected $h C T L A-4$ sequence. Final plasmid (hCTLA-4-pET) was transformed into E. coli BL21-DE3, and induced with $0.5 \mathrm{mM}$ final concentration of Isopropyl-beta-d-thiogalactopyranoside (IPTG) for 3 hours at $37^{\circ} \mathrm{C}$. Subsequently, the purification of the hCTLA-4 protein was performed using NiNTA-Qiagen affinity chromatography. Cells were harvested and resuspended in lysis buffer $\left(100 \mathrm{mM} \mathrm{NaH}{ }_{2} \mathrm{PO}_{4}, 10 \mathrm{mM}\right.$ Tris-HCl, $8 \mathrm{M}$ Urea, $\mathrm{pH}$ 8.0) and were disrupted by sonication. The cell supernatant was filtered through a $0.45 \mu \mathrm{m}$ syringe filter and was incubated with Ni-NTA resin (Qiagen, Germany), for $1 \mathrm{~h}$ on ice. Next, hCTLA-4 and resin were applied to the column. The column was washed with buffer W (100 mM NaH $2 \mathrm{PO}_{4}, 10 \mathrm{mM}$ Tris-HCl, $8 \mathrm{M}$ Urea, $\mathrm{pH}$ 6.3) and hCTLA-4 proteins were eluted with elution buffer (100 mM NaH $2 \mathrm{PO}_{4}, 10 \mathrm{mM}$ Tris-HCl, $8 \mathrm{M}$ Urea, $\mathrm{pH} 4.3$ ). Finally, $15 \%$ sodium dodecyl sulfate-polyacrylamide gel electrophoresis (SDS-PAGE) was used to assess the purity of the eluted protein. Protein samples were dialyzed against phosphate-buffered saline (PBS) buffer and were lyophilized.

Semidry western blotting (WB) method (45 minutes, $15 \mathrm{~V}$ ) was used to transfer separated recombinant hCTLA-4 protein from the $15 \%$ SDS-PAGE gel to the nitrocellulose membrane. Three times washing interval with PBS, the membrane was incubated first with rabbit anti-His antibody diluted $1: 2000$ for $\mathrm{O} / \mathrm{N}$ at room temperature (RT) and then with goat anti-Rabbit-IgG horseradish peroxidase (HRP)-conjugated antibody diluted 1:2000 for 5 hours at RT, respectively. After final washes, 4-chloro-1-naphtol and hydrogen peroxide $\left(\mathrm{H}_{2} \mathrm{O}_{2}\right)$ were applied for peroxidase-mediated staining.

\section{Immunization of $\mathrm{C}$. dromedarius}

A suspension of $100 \mu \mathrm{g}$ of recombinant hCTLA-4 protein mixed with an equal volume of complete Freund's adjuvant (for the first injection) was used to immunize a 9-month female $C$. dromedarius. Six subcutaneous injections of antigen with incomplete Freund's adjuvant, at weekly intervals, were used to raise an immune response as described previously. ${ }^{(26)}$ Peripheral blood samples were collected before each injection and sera were separated to monitor the camel immunization process by enzyme-linked immunosorbent assay (ELISA) method (preimmunized serum was harvested before injections as negative control). All washing steps were performed three times with PBS unless indicated. Briefly, $1 \mu \mathrm{g}$ hCTLA-4 protein was coated on a flat bottom 96-well microplate (Nunc MaxiSorp, Roskilde, Denmark) with sodium bicarbonate buffer ( $\mathrm{pH} 9.1$ ) overnight at $4^{\circ} \mathrm{C}$. Following that, the plate was washed and blocked with $4 \%$ skimmed milk. Subsequently, diluted sera ranging from 1:2000 to $1: 14,000$ were added to the wells and the plate was incubated for 1 hour at $37^{\circ} \mathrm{C}$. With washing intervals, wells were incubated with $100 \mu \mathrm{L}$ of 1:2000 dilution of rabbit anti-camel antibody and then with 1:2000 dilution of goat anti-rabbit-IgG HRP conjugated for 1 hour at RT, respectively. After the final washing steps, the reactions were visualized with $100 \mu \mathrm{L}$ of 3,3 ', $5,5^{\prime}-$ Tetramethylbenzidine solution.

\section{WB with camel antibody}

Purified recombinant CTLA-4 protein was run on $15 \%$ SDS-PAGE gel and then transferred to the nitrocellulose membrane through a semidry WB method (45 minutes, $15 \mathrm{~V})$. All washing steps were performed three times with PBS. Camelid sera, containing polyclonal anti-CTLA-4 antibody, were diluted 1:200 and applied on membrane for 1 hour at $37^{\circ} \mathrm{C}$. Following subsequent washing, the membrane was treated with rabbit anti-camel antibody and goat anti-rabbit-HRP-conjugated antibody, both diluted 1:2000 in PBS, for 1 hour at RT, subsequently. After the final wash, the membrane was developed by 4-chloro-1-naphtol and $\mathrm{H}_{2} \mathrm{O}_{2}$ solution.

\section{Flow cytometry}

To assess the binding potency of heavy-chain polyclonal anti-CTLA-4 antibody to CTLA-4 receptors, camelid sera were applied on MCF-7 cell line (expressing cell) and antigen-antibody interactions detected by flow cytometry. Briefly, MCF-7 cells were harvested and washed twice with ice-cold PBS $2 \%$ fetal bovine serum and adjusted to a concentration of $3 \times 10^{6} / \mathrm{mL}$. After fixation, cells were incubated with 1:200 camelid sera dilution for 1 hour on ice. To stain the attached antibodies, cells were treated with $2 \mu \mathrm{g}$ of $\mathrm{Rb}$ anti-camel for 45 minutes and then $2 \mu \mathrm{g}$ of anti-Rb FITC conjugate for 40 minutes, subsequently. Following the final wash, FITC signals were detected by a flow cytometer (Cyflow, Partec, Germany). Cells were treated with PBS for negative control. FlowJo software v.7.6 (Tree Star, USA) was used to analyze data.

\section{Immunohistochemistry}

IHC test was performed on $4 \mu \mathrm{m}$-thick paraffin-embedded breast cancer specimens (Maysa Pathology Laboratory, Iran). 

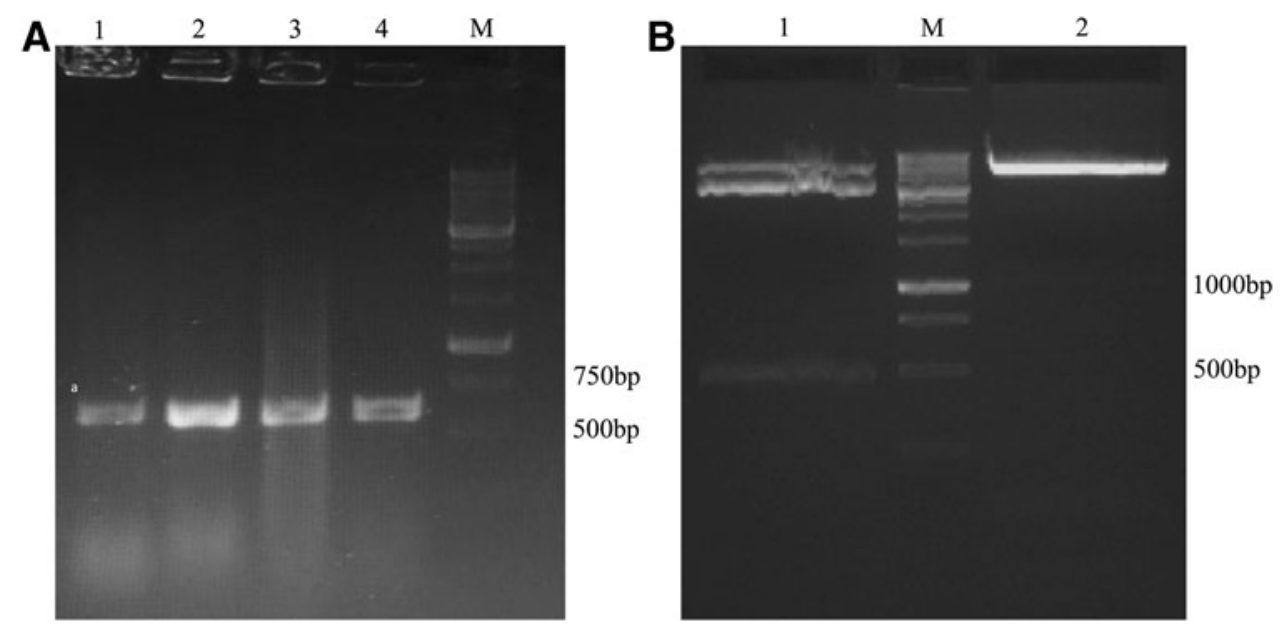

FIG. 1. Extracellular domain of hCTLA-4 gene was cloned in pET26b vector and transformed to Escherichia coli Top10. The presence of $h C T L A-4$ gene in transformed colonies was determined by colony PCR and plasmid digestion. (A) Colony PCR using universal T7 promoter and terminator primers. 1-4, Results of four different colonies, which yield a 600-bp band on $1 \%$ agarose gel; M, $1 \mathrm{~Kb}$ DNA ladder. (B) Enzyme digestion with NdeI and XhoI confirmed the subcloning of CTLA-4 gene. 1, Digested plasmid; 2, undigested plasmid; M, 1 Kb DNA ladder. CTLA-4, cytotoxic T-lymphocyte-associated protein-4; hCTLA-4, human CTLA-4; PCR, polymerase chain reaction.

Briefly, after deparaffinization with xylene, tissue sections were rehydrated in a descending ethanol series $(100 \%, 90 \%$, $70 \%$, and $50 \%$ ). Next, sodium citrate buffer was applied by Heat-Induced Epitope Retrieval method for antigen retrieving and then $3 \% \mathrm{H}_{2} \mathrm{O}_{2}$ was used for 10 minutes to eliminate endogenous peroxidase activity. To block nonspecific binding, $400 \mu \mathrm{L}$ of diluted normal goat serum was added for 30 minutes at RT. Next, slides were incubated with immunized camelid serum diluted 1:200 for $\mathrm{O} / \mathrm{N}$ at $4^{\circ} \mathrm{C}$. PBS was applied for negative control slides. Following that step, those sections were treated with rabbit anti-camel antibody diluted 1:2000 for 24 hours at $4^{\circ} \mathrm{C}$ and then $300 \mu \mathrm{L}$ (ready-to-use) anti-rabbit HRP conjugate (ZytoChem, Germany) was applied for 30 minutes at RT. For observation, tissue sections were developed with 3,3'-Diaminobenzidine and nuclei were counterstained with Hematoxylin. Finally, sections were dehydrated in an ascending ethanol gradient and mounted. Slides were observed by a microscope.

\section{Results}

\section{Cloning, expression, and purification of CTLA-4}

To express and purify hCTLA-4 protein, the DNA-coding sequence of CTLA-4 was cloned into the pET26 expression vector using the $N d e I$ and $X h o I$ cloning sites and transformed to E. coli Top10F'. Colony PCR with T7 universal primers (Fig. 1A) and restriction digestion (Fig. 1B) confirmed the transformation. Final recombinant hCTLA-4-pET26 plasmid transformed to expression host E. coli BL21-DE3. Gene expression was induced by adding $0.5 \mathrm{mM}$ final concentration
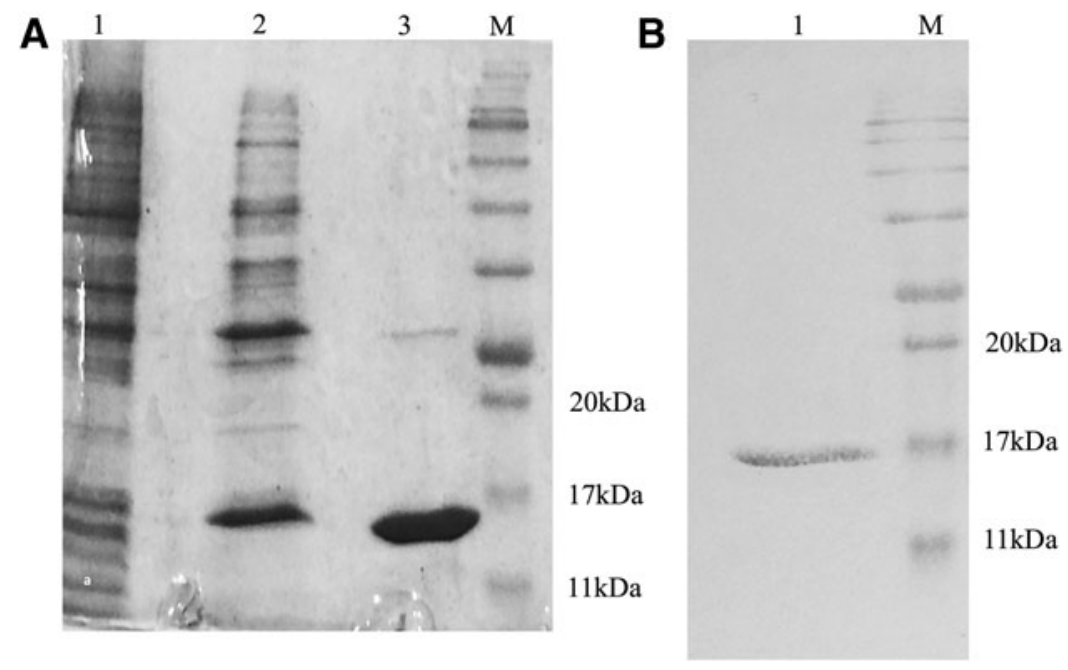

FIG. 2. Protein expression was induced with $0.5 \mathrm{mM}$ final concentration of Isopropyl-beta-d-thiogalactopyranoside and evaluated by $15 \%$ SDS-PAGE and western blotting. (A) SDS-PAGE. 1, Cells before induction (negative control); 2, induced cells; 3, purified protein with Ni. NTA column; M, protein marker. (B) Western blotting. 1, Purified protein; M, protein marker. SDS-PAGE, sodium dodecyl sulfate-polyacrylamide gel electrophoresis. 


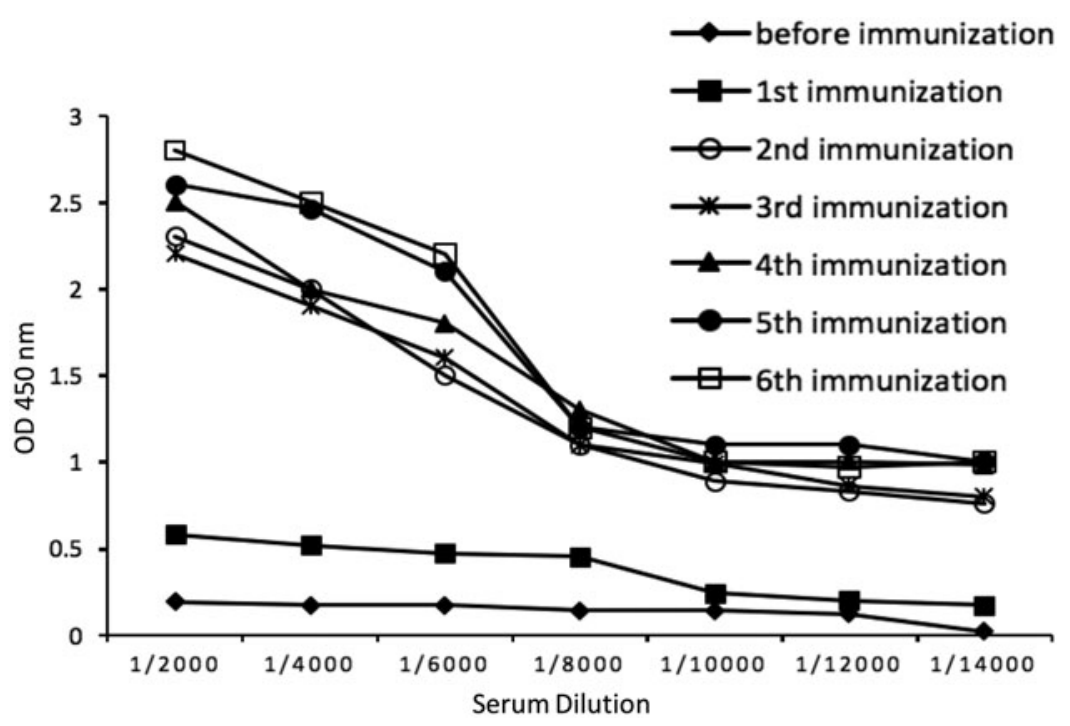

FIG. 3. Camel immunization was monitored by enzyme-linked immunosorbent assay. OD, optical density.

of IPTG and incubation for 3 hours at $37^{\circ} \mathrm{C}$ (volume of $500 \mathrm{~mL})$. The result of the $15 \%$ SDS-PAGE demonstrates the expression of our recombinant CTLA-4 corresponding to about $15.840 \mathrm{kDa}$ (Fig. 2A). Purification was performed according to the Qiagen protocol under denaturation condition. Purified protein was checked with $15 \%$ SDS-PAGE and confirmed by WB through anti-His tag (Fig. 2B). The final yield of expressed protein was $3.5 \mathrm{mg} / \mathrm{L}$ of medium.

\section{Camel immunization}

Monitoring the camelid humoral immune response was performed by using harvested blood samples. Absorbance at

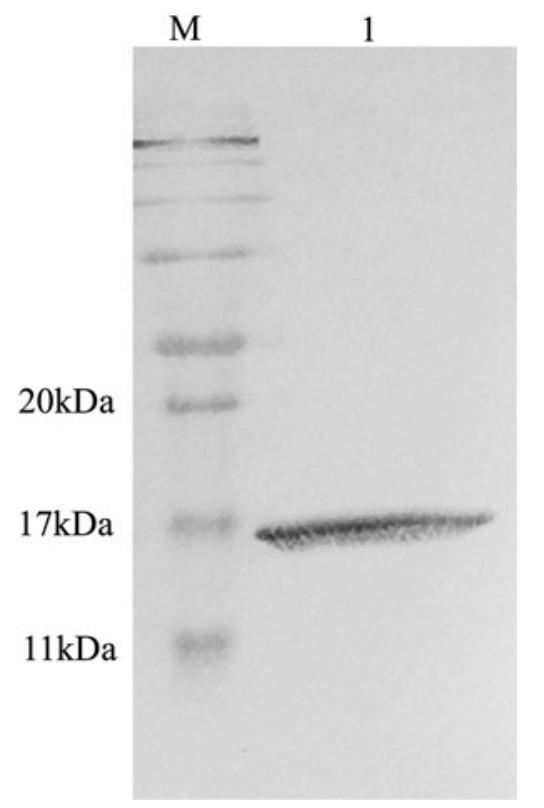

FIG. 4. Western blotting technique was used to detect interaction of CTLA-4 proteins and camelid antibodies on nitrocellulose membrane. 1, Antigen-antibody interaction; $\mathrm{M}$, protein marker.
$\mathrm{OD}_{450}$ was measured. After the second injection antibody titer has shown a significant upward trend (Fig. 3).

\section{Western blotting}

To assess the binding potency of camelid sera containing polyclonal anti-CTLA-4 antibodies to its ligand, CTLA-4

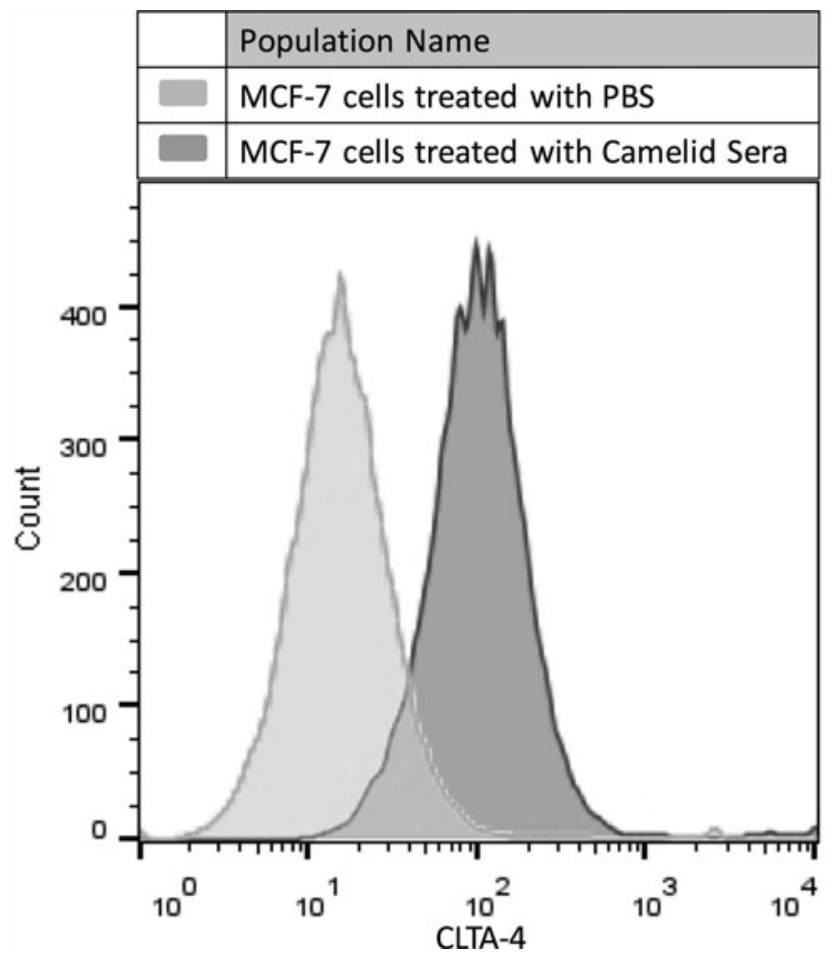

FIG. 5. Camelid sera containing pAbs performed in flow cytometry assay. Camelid antibodies were able to detect CTLA-4 antigen expressed on MCF-7 cells. Light gray line: cells treated with PBS buffer (negative control), dark gray line: cells treated with camelid sera containing pAbs. pAbs, polyclonal antibodies; PBS, phosphate-buffered saline. 
A

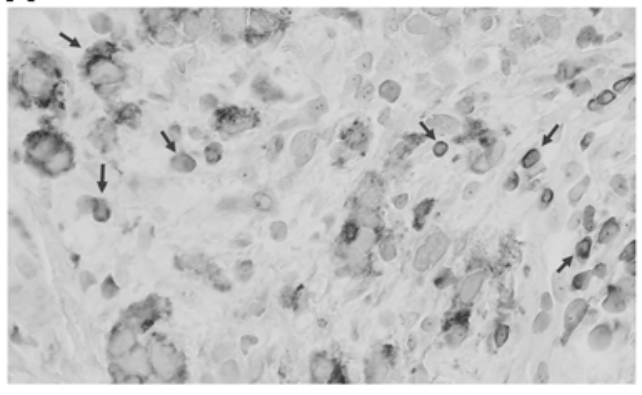

B

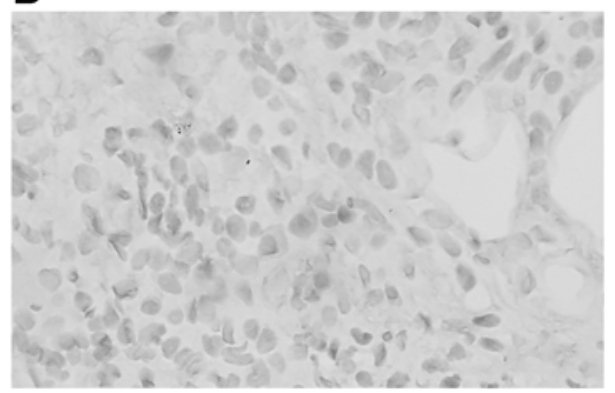

FIG. 6. Immunohistochemistry staining was performed on paraffin-embedded breast cancer sample to evaluate the binding potency of camelid antibodies. The site of antigen-antibody interactions was indicated by arrows. (A) Test; treated with camelid sera. (B) Negative control; treated with PBS. (Magnification: $400 \times$ ).

proteins, semidry WB method was used. The antigen-antibody interactions between camelid pAbs and CTLA-4 antigens were confirmed by WB (Fig. 4).

\section{Evaluation of binding potency of camelid antibodies}

The binding potency of the camelid anti-CTLA-4 antibodies was evaluated in cellular and histological grade by flow cytometry and IHC staining, respectively. Results have shown that camelid antibodies were able to detect and attach CTLA-4 receptors expressed by cancerous cells. Treated MCF-7 cells with camelid sera containing polyclonal HcAbs showed positive signals, which were indicated in the graph by the red line (Fig. 5). The paraffin-embedded sections of the breast cancer tissues stained by IHC revealed that camelid antibodies both detected and attached to CTLA-4 receptors on MCF-7 cells successfully (Fig. 6).

\section{Discussion}

CTLA-4 is a coinhibitory receptor, which acts to maintain the immune homeostasis. ${ }^{(27,28)}$ Days after T cell activation, CTLA-4 expression increases and leads to switching the immune system off. ${ }^{(3,6)}$ Furthermore, the upregulation of CTLA-4 has been reported in numerous cancers such as melanoma, nasopharyngeal carcinoma, prostate cancer, thymoma, non-small cell lung cancer, and breast cancer. ${ }^{(12,14,16,18,29,30)}$ Therefore, molecular detecting of CTLA-4 in laboratory techniques is very important.

Despite the diagnostic and therapeutic advantages of mAbs, pAbs are still the most fundamental research antibodies and have a wide variety of applications. ${ }^{(20)}$ Lower time and cost of generation, having balanced structure and tolerating environmental stresses are some advantages that facilitate the production, storage, and application of pAbs. ${ }^{(31-33)}$ The main invaluable aspect of pAbs is its multi-epitope-binding ability. ${ }^{(21)}$ Comparing with mAbs, pAbs are more effective in discovering and binding to multi-epitope antigens in different antibody-based laboratory methods such as ELISA, WB, and also IHC. ${ }^{(21)}$ Significantly, pAbs are very sensitive even to the low quantity of target proteins. ${ }^{(34)}$ The result of applying six different rabbit pAbs in WB and IHC, showed these antibodies can screen and determine various enterovirus antigens and be sensitive for some serotype classification. ${ }^{(35)}$ In another study, the activity of purified pAbs was evaluated and confirmed through different laboratory methods. Their results revealed that the raised rabbit-specific pAbs against human extracellular signal-regulated kinase 8 were able to perform as a sensitive antibody for cancer case studies. ${ }^{(36)}$ Considering the WB analyzing, our generated camelid pAbs were able to detect recombinant CTLA-4 protein on the nitrocellulose membrane (Fig. 4). Based on the purposes of researches, different animal sources are possible to be set up for immunization and generation of pAbs, for instance mouse, rat, goat, rabbit, horse, sheep, and camel. ${ }^{(22)}$

Our work showed that the prokaryotic system can be used as an effective recombinant protein production platform for the production of CTLA-4 protein. Affinity chromatography can also be used for His-tagged CTLA-4 purification.

A 9-month female $C$. dromedarius was immunized with six subcutaneous injections of the recombinant extracellular domain of hCTLA-4 receptor. Due to the big size of the host, we harvested more sera from the blood sample, in comparing with the other studies that we used rabbit and goat that probably supplied bigger pool and higher diversity of pAbs. ${ }^{(37)}$ In addition, camels produce two kinds of antibodies; conventional antibodies $(150 \mathrm{kDa})$ and $\mathrm{HcAbs}$ $(90 \mathrm{kDa})$. Indeed, the smaller size of HcAbs facilitates deep penetration through tissues and attaching to more antigen. ${ }^{(25)}$ Moreover, the antigen-binding domain of $\mathrm{HcAbs}$ is formed by a single variable domain called $\mathrm{VHH} .{ }^{(25)}$ All these features make the camel as a suitable host animal for producing pAbs. We performed ELISA, as a routine antibody-based immunoassay method to monitor the camel immunization. Data demonstrated that the camel was well immunized against the extracellular domain of CTLA-4 protein with a well titer of camelid anti-CTLA-4 antibody containing HcAbs (Fig. 3). We evaluated the potency of generated camelid antibodies in attaching to CTLA-4 receptors of cancerous cells by flow cytometry and IHC staining. Considering the results of flow cytometry, camelid sera containing polyclonal anti-CTLA-4 HcAbs were able to detect CTLA-4 receptors on MCF-7 cells and led to positive signals (Fig. 5). Besides, with no previous reports, we treated breast cancer paraffin-embedded sections with the camelid sera containing antibodies against the extracellular domain of hCTLA-4 protein. Camelid antibodies were able to detect CTLA-4 proteins on breast cancer tissues (Fig. 6). Based on the results, we estimated that IHC outcomes may be positively affected because of the sensitivity and special antigen-binding ability of camelid polyclonal HcAbs. ${ }^{(34)}$ 


\section{Conclusion}

The present study indicated that our recombinant expressed CTLA-4 is able to induce the camel immune system. Camelid sera containing polyclonal heavy-chain anti-CTLA4 antibody were potent to detect CTLA-4 protein and can be used in antibody-based assays, such as ELISA, WB, flow cytometry, and IHC, as the cellular and histological laboratory methods.

\section{Acknowledgments}

The authors wish to express their deepest gratitude to Ehsan Alirahimi and Hajarsadat Ghaderi for their technical support.

\section{Author Disclosure Statement}

No competing financial interests exist.

\section{Funding Information}

This study was financially supported by National Institute for Medical Research Development (NIMAD) grant number 943314 and Pasteur Institute of Iran grant number 994.

\section{References}

1. Brunet JF, Denizot F, Luciani MF, Roux-Dosseto M, Suzan M, Mattei MG, and Golstein P: A new member of the immunoglobulin superfamily-CTLA-4. Nature 1987;328: 267-270.

2. Walunas TL, Lenschow DJ, Bakker CY, Linsley PS, Freeman GJ, Green JM, Thompson CB, and Bluestone JA: CTLA-4 can function as a negative regulator of $\mathrm{T}$ cell activation. Immunity 1994;1:405-413.

3. Buchbinder EI, and Desai A: CTLA-4 and PD-1 pathways: Similarities, differences, and implications of their inhibition. Am J Clin Oncol 2016;39:98-106.

4. Wing K, Yamaguchi T, and Sakaguchi S: Cell-autonomous and -non-autonomous roles of CTLA-4 in immune regulation. Trends Immunol 2011;32:428-433.

5. Wing K, Onishi Y, Prieto-Martin P, Yamaguchi T, Miyara M, Fehervari Z, Nomura T, and Sakaguchi S: CTLA-4 control over Foxp3+ regulatory $\mathrm{T}$ cell function. Science 2008;322:271-275.

6. Egen JG, Kuhns MS, and Allison JP: CTLA-4: New insights into its biological function and use in tumor immunotherapy. Nat Immunol 2002;3:611-618.

7. Chambers CA, Kuhns MS, Egen JG, and Allison JP: CTLA-4-mediated inhibition in regulation of $\mathrm{T}$ cell responses: Mechanisms and manipulation in tumor immunotherapy. Annu Rev Immunol 2001;19:565-594.

8. Hoenicke L, and Zender L: Immune surveillance of senescent cells-biological significance in cancer- and noncancer pathologies. Carcinogenesis 2012;33:1123-1126.

9. Pardoll DM: The blockade of immune checkpoints in cancer immunotherapy, Nature reviews. Cancer 2012;12:252-264.

10. Pistillo MP, Tazzari PL, Palmisano GL, Pierri I, Bolognesi A, Ferlito F, Capanni P, Polito L, Ratta M, Pileri S, Piccioli M, Basso G, Rissotto L, Conte R, Gobbi M, Stirpe F, and Ferrara GB: CTLA-4 is not restricted to the lymphoid cell lineage and can function as a target molecule for apoptosis induction of leukemic cells. Blood 2003;101:202-209.

11. Contardi E, Palmisano GL, Tazzari PL, Martelli AM, Fala F, Fabbi M, Kato T, Lucarelli E, Donati D, Polito L, Bo- lognesi A, Ricci F, Salvi S, Gargaglione V, Mantero S, Alberghini M, Ferrara GB, and Pistillo MP: CTLA-4 is constitutively expressed on tumor cells and can trigger apoptosis upon ligand interaction. Int J Cancer 2005;117: 538-550.

12. Huang PY, Guo SS, Zhang Y, Lu JB, Chen QY, Tang LQ, Zhang L, Liu LT, Zhang L, and Mai HQ: Tumor CTLA-4 overexpression predicts poor survival in patients with nasopharyngeal carcinoma. Oncotarget 2016;7:13060-13068.

13. Tsai HF, and Hsu PN: Cancer immunotherapy by targeting immune checkpoints: Mechanism of $\mathrm{T}$ cell dysfunction in cancer immunity and new therapeutic targets. J Biomed Sci 2017;24:35.

14. Shah KV, Chien AJ, Yee C, and Moon RT: CTLA-4 is a direct target of Wnt/beta-catenin signaling and is expressed in human melanoma tumors. J Invest Dermatol 2008;128: 2870-2879.

15. Salvi S, Fontana V, Boccardo S, Merlo DF, Margallo E, Laurent S, Morabito A, Rijavec E, Dal Bello MG, Mora M, Ratto GB, Grossi F, Truini M, and Pistillo MP: Evaluation of CTLA-4 expression and relevance as a novel prognostic factor in patients with non-small cell lung cancer. Cancer Immunol Immunother 2012;61:1463-1472.

16. Yu H, Yang J, Jiao S, Li Y, Zhang W, and Wang J: Cytotoxic $\mathrm{T}$ lymphocyte antigen 4 expression in human breast cancer: Implications for prognosis. Cancer Immunol Immunother 2015;64:853-860.

17. Hu P, Liu Q, Deng G, Zhang J, Liang N, Xie J, and Zhang $\mathrm{J}$ : The prognostic value of cytotoxic T-lymphocyte antigen 4 in cancers: A systematic review and meta-analysis. Sci Rep 2017;7:42913.

18. Santoni G, Amantini C, Morelli MB, Tomassoni D, Santoni M, Marinelli O, Nabissi M, Cardinali C, Paolucci V, Torniai M, Rinaldi S, Morgese F, Bernardini G, and Berardi R: High CTLA-4 expression correlates with poor prognosis in thymoma patients. Oncotarget 2018;9:16665-16677.

19. Gao Y, Huang X, Zhu Y, and Lv Z: A brief review of monoclonal antibody technology and its representative applications in immunoassays. J Immunoassay Immunochem 2018;39:351-364.

20. Weller MG: Quality issues of research antibodies. Anal Chem Insights 2016;11:21-27.

21. Ascoli CA, and Aggeler B: Overlooked benefits of using polyclonal antibodies. Biotechniques 2018;65:127-136.

22. Delahaut P: Immunisation-Choice of host, adjuvants and boosting schedules with emphasis on polyclonal antibody production. Methods 2017;116:4-11.

23. Tillib SV, Vyatchanin AS, and Muyldermans S: Molecular analysis of heavy chain-only antibodies of Camelus bactrianus. Biochemistry (Mosc) 2014;79:1382-1390.

24. Harmsen MM, and De Haard HJ: Properties, production, and applications of camelid single-domain antibody fragments. Appl Microbiol Biotechnol 2007;77:13-22.

25. Siontorou CG: Nanobodies as novel agents for disease diagnosis and therapy. Int J Nanomed 2013;8:4215-4227.

26. Behdani M, Zeinali S, Khanahmad H, Karimipour M, Asadzadeh N, Azadmanesh K, Khabiri A, Schoonooghe S, Anbouhi MH, and Hassanzadeh-Ghassabeh G: Generation and characterization of a functional Nanobody against the vascular endothelial growth factor receptor-2; angiogenesis cell receptor. Mol Immunol 2012;50:35-41.

27. Krummel MF, and Allison JP: CD28 and CTLA-4 have opposing effects on the response of $\mathrm{T}$ cells to stimulation. J Exp Med 1995;182:459-465. 
28. Fife BT, and Bluestone JA: Control of peripheral T-cell tolerance and autoimmunity via the CTLA-4 and PD-1 pathways. Immunol Rev 2008;224:166-182.

29. Kwek SS, Dao V, Roy R, Hou Y, Alajajian D, Simko JP, Small EJ, and Fong L: Diversity of antigen-specific responses induced in vivo with CTLA-4 blockade in prostate cancer patients. J Immunol (Baltimore, Md.: 1950) 2012; 189:3759-3766.

30. Antczak A, Pastuszak-Lewandoska D, Gorski P, Domanska D, Migdalska-Sek M, Czarnecka K, Nawrot E, Kordiak J, and Brzezianska E: CTLA-4 expression and polymorphisms in lung tissue of patients with diagnosed non-smallcell lung cancer. Biomed Res Int 2013;2013:576486.

31. Wang XZ, Coljee VW, and Maynard JA: Back to the future: Recombinant polyclonal antibody therapeutics. Curr Opin Chem Eng 2013;2:405-415.

32. Kheddo P, Tracka M, Armer J, Dearman RJ, Uddin S, van der Walle CF, and Golovanov AP: The effect of arginine glutamate on the stability of monoclonal antibodies in solution. Int J Pharm 2014;473:126-133.

33. Ferrara F, D'Angelo S, Gaiotto T, Naranjo L, Tian H, Graslund S, Dobrovetsky E, Hraber P, Lund-Johansen F, Saragozza S, Sblattero D, Kiss C, and Bradbury AR: Recombinant renewable polyclonal antibodies. MAbs 2015;7: $32-41$.

34. Ivell R, Teerds K, and Hoffman GE: Proper application of antibodies for immunohistochemical detection: Antibody crimes and how to prevent them. Endocrinology 2014;155: 676-687.
35. Kotani O, Iwata-Yoshikawa N, Suzuki T, Sato Y, Nakajima N, Koike S, Iwasaki T, Sata T, Yamashita T, Minagawa H, Taguchi F, Hasegawa H, Shimizu H, and Nagata N: Establishment of a panel of in-house polyclonal antibodies for the diagnosis of enterovirus infections. Neuropathology 2015;35:107-121.

36. Cai NL, Lau ATY, Yu FY, Wu DD, Dai LJ, Mo HY, Lin $\mathrm{CM}$, and $\mathrm{Xu} \mathrm{YM}$ : Purification and characterization of a highly specific polyclonal antibody against human extracellular signal-regulated kinase 8 and its detection in lung cancer. PLoS One 2017;12:e0184755.

37. Gerdts V, Wilson HL, Meurens F, van Drunen Littel-van den Hurk S, Wilson D, Walker S, Wheler C, Townsend H, and Potter AA: Large animal models for vaccine development and testing. ILAR J 2015;56:53-62.

Address correspondence to: Mahdi Behdani

Biotechnology Research Center Venom and Biotherapeutics Molecules Laboratory

Pasteur Institute of Iran Tehran 1316543551

Iran

E-mail: behdani73042@yahoo.com; behdani@pasteur.ac.ir

Received: July 7, 2019

Accepted: September 20, 2019 